other matronly woman, in a white sari. Podike thaye maga? Yaan ulley atha, iththe daaktarla battheru, nanna yaarla bodiicchi? - Why panic son, I am here now, and now we have the doctor too, who else do we need? The lingo was Tulu, an ancient Dravidian dialect (and, for the curious, the mother tongue of actress Aishwarya Rai). The term maga - son - is used beyond gender for daughters, too, as a form of endearment.

I heaved a silent sigh. Thank heaven for small mercies. She looked like a midwife, a native nursemaid. I perceived that she read my face and saw panic written on it in capital letters. She bade all to leave us alone and sat down beside the mother-to-be, who now lay

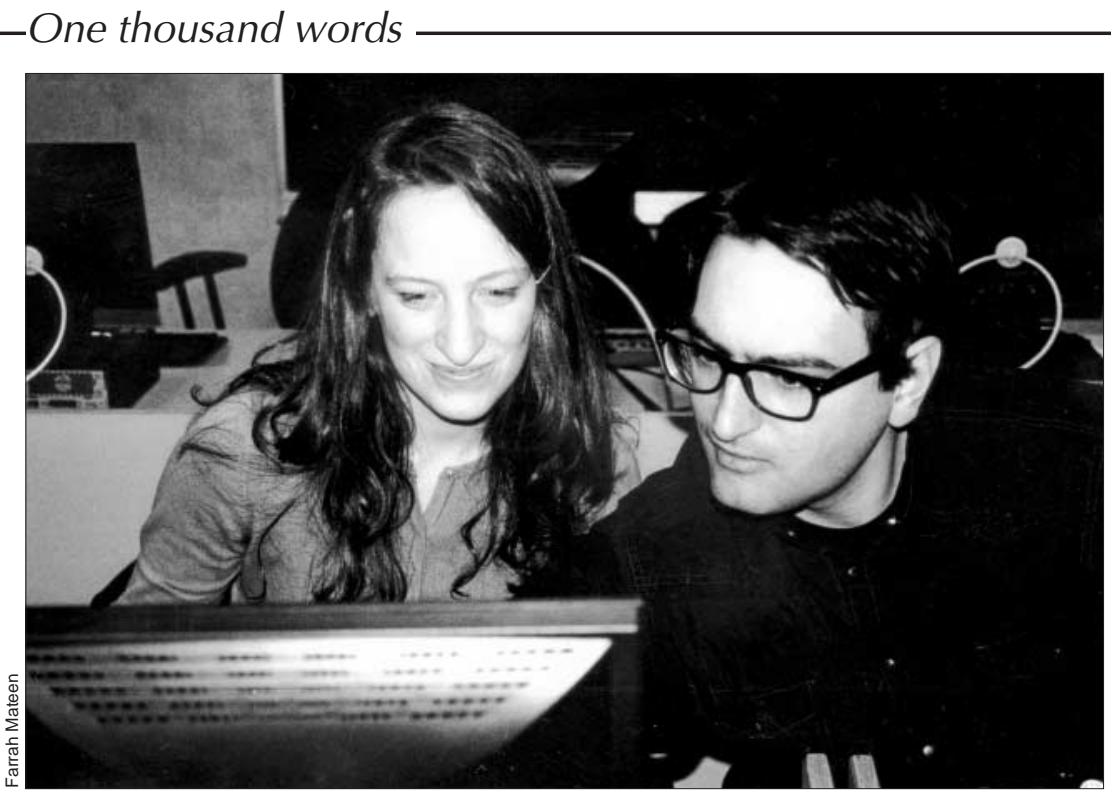

Matched? In 2005 more than 1400 graduating medical students participated in the Canadian Resident Matching Service, best known by its acronym CaRMS. CaRMS held its first residency match in 1970, when the undergraduate dean of the local medical college handed out an envelope to each participating medical student. The envelope contained the match result (both the specialty and the city) that would secure or unravel the student's future plans. Since 1970 the residency matching process has become increasingly sophisticated, allowing for the matching of couples, the monitoring of document submissions and, in 1998, going online. This photo was taken at the University of Saskatchewan at 11:01 am on Match Day. Whether learning the match outcome involves tearing open an envelope or madly hitting "reload" on the Web site, reactions remain unchanged. Courtney Meier (left) will study family medicine at the University of Saskatoon, and Cory Tremeer will study radiology at Queen's University in Kingston. They remind you not to forget your online password for the Web station on the day of the match. - Farrah Mateen, Class of 2005, College of Medicine, University of Saskatchewan, Saskatoon, Sask. fort, and egged on the mother to be. Nanna onji chooru maga - Just a little more, son. Presently, amid the groans and grimaces, I heard a kitten-like cry.

A baby girl. A perfectly healthy neonate. A host of new lamps were lit, a Petromax lantern suddenly coughed into life, the family was in ecstasy. Neighbours converged, laughter and bonhomie pervaded. I helped the midwife deliver the placenta and snipped the cord that bound baby to mother. From now on the bond between them would be invisible, but of a higher plane. The baby's cry had Annadurai and Gowri on alert too. Their tails swished to and fro in slow motion. There was a banana-leaf plate with a home jaggery-based specialty and a steel mug of Horlicks for me. Discretely, a folded twenty-rupee note was pressed into the palm of the nurseamma, who grinned, her betel-stained incisors aglint. Many pats on my back, and many rounds of Thanks Daaktarey later, I headed back. The new father walked with me, insisting on holding my stick in one hand and my lantern in the other: his humble, rural way of expressing gratitude.

I wonder how or why the trickle direction meant so much to the unlettered village nurse. Is it that when the overflow direction is toward the toes, the uterus is still undescended, and when suddenly the flow direction is reversed, the organ level has dipped? Could this woman have determined the onset of the second stage through this simple method? Or was I just a witness to a superstitious ritual? I am uncertain still. I am certain though, that there is more lore and logic in an indigenous barefoot doctor's armamentarium than I have seen in the tomes of modern medicine. In both demonstrating and inspiring raw confidence, few modern doctors can hold a candle to the talents of the unschooled indigenous dais of subcontinental Asia.

\section{Arunachalam Kumar}

Professor and Head

Department of Anatomy

Kasturba Medical College

Magalore, India 